\title{
Pioneers across war zones: The lived acculturation experiences of US female military expatriates
}

\author{
Kelly Fisher ${ }^{\mathrm{a}, *}$, Kate Hutchings ${ }^{\mathrm{b}}$, Luisa Helena Pinto ${ }^{\mathrm{c}}$ \\ a West Chester University Pennsylvania, West Chester, PA, USA \\ b Griffith University, Gold Coast campus, Australia \\ c Universidade do Porto, Porto, Portugal
}

\section{A R T I C L E I N F O}

\section{Keywords:}

Female expatriate

Extreme context

Lived experience

Military

Phenomenology

\begin{abstract}
A B S T R A C T
This exploratory study focuses on the lived acculturation experiences of United States (US) female career military expatriates who worked and lived in combat settings across five war zones. Based on an analysis of oral histories that spanned over 60 years, the research revealed that these pioneering women had a strong commitment to their profession, and that this, along with camaraderie, facilitated their adaptation to living conditions characterized by extreme danger, nominal domestic comforts, and unrelenting work requirements in culturally unfamiliar contexts. The research identified the multiple physical and psychological stressors of living and working as a female in a war zone and the variety of coping strategies employed for acculturation, particularly the prominent role of relational support from family and friends, and a combination of personal coping mechanisms (such as crying or compartmentalization) and religious faith. As extant expatriate research has overwhelmingly focused on male executives in multinational corporations, this research is significant in extending the literature to an analysis of the public sector, specifically women deployed overseas in highly dangerous settings and who were pioneering in both their roles in the military and as non-traditional expatriates at a time when few women worked internationally.
\end{abstract}

(c) 2015 Elsevier Ltd. All rights reserved.

\section{Introduction}

Extant research has largely examined expatriation from the perspective of employees (typically males) in multinational corporations undertaking traditional expatriate assignments (see Harrison, Shaffer, \& Bhaskar-Shrinivas, 2004). In contrast, this research analyzes the oral histories of United States (US) female career military expatriates deployed across five war zones and a 60-year span and extends the general expatriation literature by examining female military expatriate acculturation and their coping strategies in an extreme context (i.e. a war zone), which is defined as a life-threatening environment characterized by physiological, cognitive, and emotional stressors (Hannah, Uhl-Bien, Avolio, \& Cavarretta, 2009). More particularly, it extends an erstwhile concentration on business expatriates (Selmer \& Fenner, 2009) to public sector employees by focusing on career military professionals who were required to accept task and geographic relocation as dictated by operational needs.

\footnotetext{
* Corresponding author.

E-mail addresses: KFisher@wcupa.edu (K. Fisher), k.hutchings@griffith.edu.au (K. Hutchings), Ihpinto@fep.up.pt (L.H. Pinto).
} 
Doucerain, Dere, and Ryder (2013: p. 4) urge future research "to take into account the environment that acculturating individuals navigate and thus to focus on the concrete nature of their lived experience". Doucerain et al. (2013: p. 3) further argue that there is a need for a deeper exploration of the 'micro-context' or the "immediate, concrete, local conditions of daily life". Our study responds to the call to focus on the "lived acculturation experience" (Harvey \& Moeller, 2013: p. 3 ) by fore fronting the hostile, dangerous setting in which military expatriates are embedded in order to account for the greater complexity of relationships and behavior occurring in an extreme context (Fisher \& Hutchings, 2013). As noted in an exploratory study on the Irish Defence Forces during an overseas peacekeeping mission, the "sending organization and the receiving environment play a major role in the degree of challenge and stress an assignment entails" (Crowley-Henry \& Heaslip, 2014: p. 4). Moreover, there has been limited consideration given to acculturation of public-sector organizations such as the military despite their frequent operation in multi-national alliances (Crowley-Henry \& Heaslip, 2014; Selmer \& Fenner, 2009).

Through an exploration of the experiences of female military expatriates across a range of wars over the past 60 years, our study informs present understanding of modern expatriate assignments in terms of impact of location and timing, in addition to providing insight into variations in the extent to which the women's acculturation was shaped by changing societal norms and organizational policies. Our focus on career military also facilitated the exploration of individuals' commitment to their organization and role in their acculturation. The women were pioneering in both their roles as military professionals in forward combat settings and as female non-traditional expatriates during times in which international career opportunities were scant for most women.

\section{Literature review}

\subsection{Military expatriates}

Along with those involved in humanitarian efforts, peacekeeping missions, and civil political conflicts, military expatriates work in extreme contexts that are dangerous, highly dynamic, and that present multiple stressors (Hannah et al., 2009). Despite a long tradition of sending public sector personnel overseas for a variety of purposes, such as diplomatic and military service (Stening, 1994), research on public sector expatriates and their working conditions has been limited (Fenner \& Selmer, 2008) despite the importance of understanding the contextual influences associated with an organization's role in society (Nutt, 2006). As defined here, organizationally-assigned expatriates are individuals tasked to work and live for a fixed period in a country of the organization's choice (Tharenou, 2009), thus military personnel share certain features with traditional expatriates. Nonetheless, they are also distinct from those in the private, for-profit, sector as detailed below.

One significant difference is that overseas postings are an integral part of a military career path, despite the ambiguity of future work locations (DoA, 2010). Moreover, limited research has acknowledged that there are differences in level of commitment (and, perhaps, motivation) between the public and private sector (see Fenner \& Selmer, 2008; Selmer \& Fenner, 2009). In this regard military career expatriates are similar to some other employees in the public (and not-for-profit) sector who accept that commitment to their chosen career implies the possibility of relocation to a dangerous area. For example, some humanitarian aid workers may choose their location, while others will be relocated according to organizational need. Moreover, while religious missionaries may have greater interaction with locals than other expatriates (see Navara \& James, 2002), their faith commitment means sometimes accepting postings into areas of civil conflict. However, it is also recognized that not all corporate employees necessarily have a choice (or feel that they have a choice) in accepting or rejecting an assignment. Indeed, some research (see Bolino, 2007; Stahl, Miller, \& Tung, 2002) has suggested that if employees reject an offer of an international assignment that it can be perceived as lack of organizational commitment and affect their future promotion prospects or other opportunities. However, in direct contrast military career expatriates must willingly accept relocation as part of their commitment to active military service.

Depending on the nature of the military assignment (as driven by organizational needs) in conjunction with the individual's own specific training and position (e.g. special forces, diplomatic corps, intelligence), the military expatriate may be required to undertake multiple short-term international assignments (STIAs) (Crowley-Henry \& Heaslip, 2014) or they may occupy any one of the three categories of expatriate manager roles (propatriate, flexpatriate, and expatriate) characterized by a focused commitment on the organization (see McPhail, Fisher, Harvey, \& Moeller, 2012). Successful career military personnel 'sign on' to a 20-year + career, thus a commitment to the organization must be made early. Lastly, during a time of war, military personnel are generally unaccompanied by spouse/family when deployed and are rotated out of a combat setting every 12 to 18 months and returned stateside due to the psychological and physical demands of serving in an area under 'hostile fire or imminent danger' (National Research Council, 2012).

\subsection{Female expatriation and female military expatriates}

A 25-year meta-analysis of female expatriation conducted by Altman and Shortland (2008) reported that three key trends continue to be considered barriers to women's expatriation, namely: perceived resistance from the host country to accepting women in managerial roles; organizational resistance to selecting women and limited support when working internationally; and women's own disinterest in taking international assignments. Other studies (Fischlmayr \& Kollinger, 2010; Mäkelä, Känsalä, \& Suutari, 2011) suggest that while on assignment women may experience different or additional 
challenges to their male colleagues in respect to caring responsibilities and lack of extended family support, and dual career conflict issues.

Current and ongoing debates concerning male and female differences in overseas assignments are also of relevance to our research. For example, there is some evidence that women expatriates adjust similarly (Selmer \& Leung, 2003) or even more effectively than men (Halsberger, 2007; Tung, 2004). Conversely, other research suggests that women's overall job satisfaction may be lower (Culpan \& Wright, 2002), and they appear to struggle more with the stress and isolation of an overseas posting (Tung, 1998).

Yet, within this context some women have had international careers over an extended period. Once such area is in extreme contexts where women have worked actively in the not-for-profit sector in peacekeeping and missionary roles and as aid workers (Harmer, Stoddard, \& Toth, 2013). In the military, women have historically served important functions, particularly in major wars, in traditional roles as nurses and administrators (Nuciari, 2000). While the expatriate literature has given reasonable consideration to women expatriates and the particular challenges they face (see Altman \& Shortland, 2008; McPhail et al., 2012), there has been a dearth of research on women in expatriate roles in the military-a significant theoretical limitation and practical oversight given their longstanding contributions and service. In response, a few studies have begun to identify potential gender differences among combat-deployed veterans (Maguen, Ren, Bosch, Marmar, \& Seal, 2010; Street et al., 2013). In a national survey that included 1207 female veterans who were deployed to Afghanistan (OEF) and Iraq (OIF), Street et al. (2013: p. 556) suggested that: "Experiences of sexual harassment and assault during military service are a critical issue when considering the traumatic stress burden of female service members. . Military women are more likely than their male counterparts to experience non-sexual gender-based harassment and a lack of social support from military peers and leadership."

While these prior survey-based studies identified some of the gender-related challenges for female military in forward combat units during the Gulf wars, what is missing is the women's own interpretation of their lived acculturation experiences across different war zones. Given the extended engagement of US military forces in the Gulf, coupled with the expanding role of American women in forward-combat roles (Street et al., 2013), there is a pressing need to understand the acculturation experiences of female veterans.

\subsection{Acculturation}

In the extant literature, there are several competing views on the meaning of acculturation, which may be broadly grouped at either the cultural (group) or psychological (individual) level (Berry, 2005). Our study is focused at the individual level as defined by Graves (1967) who first introduced the concept of psychological acculturation as the learning process experienced by an individual who is a participant in a culture contact situation. According to Aycan (1997), the acculturation process is comprised of four distinct phases: pre-departure preparation; post-arrival initial contact; appraisal and coping; and psychological and adjustment outcomes. Adjustment is typically conceptualized as a multi-dimensional phenomenon that assesses the degree of fit or psychological comfort between the expatriate and the environment (Black, Mendenhall, \& Oddou, 1991; Harrison et al., 2004) and is considered a central construct for the study of expatriates (Thomas \& Lazarova, 2006). The three-facet (general, interaction, and work) model of expatriate adjustment (Black, 1988; Black \& Stephens, 1989) was used as the theoretical framework for this study. General adjustment refers to expatriates coping with broader environmental conditions such as living quarters, climate, food, and dress. Interactional adjustment refers to the extent to which individuals comfortably socialize and interact with locals in a work and non-work context. Finally, work adjustment more narrowly pertains to work-related responsibilities, performance, and expectations. This framework has been examined through decades of research and is arguably the most influential and cited theoretical treatment of expatriate adjustment experiences (Takeuchi, 2010). Moreover, the model offers a context-specific approach that incorporates the stress perspective. Our analysis of the lived experience of acculturation offers an empirical lens through which to examine the "process by which individuals deal with the inevitable culture shock of expatriate assignments and the characteristics of individuals and situations that allow them to perform well" (Thomas \& Lazarova, 2006: p. 260).

Given that expatriate assignments create a great deal of uncertainty for the individual, theories of stress management seem particularly relevant to understanding expatriate adjustment (Black et al., 1991) in a highly dangerous and dynamic context as forefronted in this study. The challenges and difficulties experienced by expatriates are frequently referred to as acculturative stress (Organista, Marin, \& Chun, 2010). Acculturative stress emphasizes individual differences in how people respond to the constellation of pressures of change and the presence of unfamiliar social and physical environmental conditions, such as incongruent cultural values and practices, language difficulties, and discrimination (Gil, Vega, \& Dimas, 1994). In this sense, acculturative stress is a reaction in response to life events that are rooted in the experience of acculturation. Drawing on the broader stress and adaptation paradigms (e.g., Lazarus \& Folkman, 1984), this approach underpins the process of how individuals deal with acculturative problems on first encounter and over time. Successful strategies in coping with these stressful conditions are thought to be related to an overall sense of well-being along with physical and mental health correlates (Organista et al., 2010). Social support within and outside the family has also been found to act as a buffer to problems in adapting to unfamiliar contexts (see Williams \& Berry, 1991).

Of relevance to our study, Caligiuri and Lazarova (2002) proposed a model to describe how female expatriates, specifically, might develop and employ relationships as part of their acculturative process. They suggested that women could draw on various sources of social interaction and support (such as family, colleagues, host nationals) that would address a multiplicity 
of needs, including emotional, informational, and instrumental. Unsurprisingly, there are large variations in how individuals acculturate (or develop acculturation strategies) (Berry, 2005). The complexity of the acculturating process is confounded by the typical requirement for military personnel to reside on base, which can be seen as a form of 'expatriate ghetto'.

\subsection{Expatriate ghettos}

Some international assignees may live in what is termed an 'expatriate ghetto', which is associated with the less-desirable, separation mode of acculturation (see Berry \& Kailin, 1995). In some instances this may be refer to the actual practice of living in compounds exclusively designed for expatriates (Björkman \& Schaap, 1994) for reasons of physical security such as situations where there is political or civil unrest. In other cases, an expatriate ghetto may refer to the practice of expatriates choosing to live in the same area as other expatriates and spending their non-work/social hours with other expatriates (see Hutchings, Michailova, \& Harrison, 2013). The 'ghettos' may provide valuable support in the adjustment process through reducing isolation (see Kealey, 2004) and creating relationships with other expatriates, yet for military expatriates such relationships may be short lived as people are rotated in and out of assignments. Nonetheless, it is acknowledged that even for expatriates who live in these ghettos, there are varying degrees of interaction with locals with some cultural contexts specifically preventing women from interacting with locals, especially men (see Hutchings et al., 2013).

For those who work in extreme contexts such as humanitarian workers and journalists, there may be greater need to build trust with local people to achieve their assignment requirements and hence living in a ghetto would be counter-productive. For military personnel the situation may not always be clear in that there may be cases where working effectively with locals and ascertaining "who is the enemy" necessitates greater interaction. On the other hand, deployments to hazardous and culturally distant contexts might necessitate the maintenance of an expatriate ghetto 'mentality' based on both security concerns and recognizing that the support and camaraderie of fellow military expatriates as essential for psychological wellbeing. In some cases there may be a sense that those who work in extreme contexts simply have a job to do and they need to go in, do it, and leave-and building relationships and acculturating is not a key element of the assignment focus. This research provides greater insights into female military expatriates and their lived acculturation experiences in extreme contexts by exploring the following research questions:

RQ 1: What are the general, interaction, and work adjustment patterns of female career military expatriates as shaped by an extreme context?

RQ 2: What are the stressors of female career military expatriates in an extreme context and how are these stresses mitigated?

\section{Research method}

\subsection{Research approach}

A phenomenological approach to undertaking research, founded by Edmund Husserl (1859-1938), is based on an epistemological philosophy that emphasizes one's 'lived experience' in the structuring of consciousness and subjectivity (Husserl, 1962). A central assumption that underpins phenomenology is that humans seek meaning from their own and other's experiences, an organizing process that is inherently contextual. Meaning, or knowledge, is seen as a "product" of human experience and "to understand the meanings another assigned to his or her actions require[s] that these meanings be placed within context" (Smith, 1983: p. 8). Utilizing a phenomenological approach, this study drew on the insights and experiences of female military expatriates and thus exemplifies the use of oral histories for understanding a present-day phenomenon (Berg, 1995). Moreover, the use of qualitative data in the form of first-person recall allows for contextually rich identification, description, and explanation-generation (Crabtree \& Miller, 1992). The use of oral histories in conducting this research was further necessitated given the danger and difficulty associated with undertaking field research in extreme contexts.

\subsection{Description of sample}

Oral histories are a form of primary data. Primary data are defined as first-hand testimony or direct evidence concerning a topic under investigation and include autobiographies, memoirs, and oral histories (Goodman \& Kruger, 1988). The source for the oral interviews for this project was the Veterans History Project (VHP) Collection, American Folklife Center, Library of Congress, US. The VHP is primarily an oral history program that collects and preserves the firsthand interviews of US wartime veterans. All the interviews that are available through the VHP website were collected after Congress approved funding for the project in 2000. The data is publicly available through the VHP website (http://www.loc.gov/vets/). Under the fair use doctrine of the US copyright statute (Title 17 of the US Code) it is permissible to use limited portions of a work including quotes, for purposes such as commentary, criticism, news reporting, and scholarly reports.

Veterans' oral histories were recorded in person by friends or family who were provided with a VHP field kit that included instructions on how to conduct an interview as well as a list of broad question areas that included the following topics: biographical details, early days of service, wartime service, experiences at the end of the war/end of military service, and personal reflections. The minimum requested length for interviews was $30 \mathrm{~min}$, although the VHP frequently accepted 
Table 1

Attributes of female veteran sample.

\begin{tabular}{|c|c|c|c|c|}
\hline Demographics & Medical & Technical & Support & Total \\
\hline \multicolumn{5}{|l|}{ Military ranking } \\
\hline Enlisted & 0 & 1 & 4 & 5 \\
\hline Officer & 13 & 3 & 3 & 19 \\
\hline \multicolumn{5}{|l|}{ War zone } \\
\hline WWII & 3 & 0 & 0 & 3 \\
\hline Korean War & $2(1)$ & 0 & 0 & $2(1)$ \\
\hline Vietnam War & 4 & 0 & 1 & 5 \\
\hline Gulf Wars & 3 & 4 & 7 & 14 \\
\hline Multi-wars* & (1) & 0 & 0 & (1) \\
\hline
\end{tabular}

"The number in parentheses shows the veteran who was in two combat zones (called 'multi-war').

shorter interviews, particularly if they were with older veterans or had accompanying documentation (as advised in a phone conference conducted by one of the researchers on 21st July 2014). As of August 2013, there were 138 interviews of female veterans encompassing their recollections from WWII to the current war in Afghanistan.

The oral histories presented by the women are similar to semi- or open-ended interviews in that they provided opportunity for the interviewer and/or interviewee to explore or expand on a tangent line of inquiry. Such an approach allowed the interviewees to focus on issues that they felt were salient. We believe that this approach provides richness and depth to the data, which is critical in capturing the "lived acculturation" experiences.

During the course of this research all 138 interviews were downloaded and 45 interviews were categorized as occurring in a forward combat war zone, of which 24 were career military and 21 were non-career. All 24 career interviews that were analyzed for this research were purposefully selected from the combat/career category to highlight the experience of female career military and to preserve homogeneity of the sample. The interviews were further categorized by war zone, occupation (i.e., medical, technical, support), and military ranking (enlisted/officer) to facilitate comparison. These categorizations are shown in Table 1. Additionally, the "Gulf Wars" designation is inclusive of multiple combat operations that occurred mainly in the Iraq and Afghanistan war zones. Both war zones were aggregated due to the overlapping timeframe of the Gulf Wars I and II (1990; 2003-2011) and the War in Afghanistan (2001 to present) and the similarity of the physical operating environments and Islamic cultural context.

The sample is heavily weighted toward the Gulf War veterans and officer corps due to the historically limited participation of women in the military until the 1980s (Segal \& Segal, 2004), especially in forward combat units (DoD, 2010). According to a report by the Institute of Medicine (IOM, 2012), only 0.2\% of service members in Vietnam were women compared with 12.7\% of the deployed force in Afghanistan's Operation Enduring Freedom (OEF) and Operation Iraqi Freedom (OIF) (Maguen et al., 2010). We also note that only a small minority of women were able to remain in the military once legal limitations on women's participation were reintroduced at the end of the three earlier wars (Segal \& Segal, 2004), thus there were very limited numbers of veterans who met our selection criteria. Nonetheless, analysis of the rich, historical data revealed important differences in the acculturation experiences between veterans who served in the first three wars and those who served in the latter Gulf wars.

\subsection{Data analysis}

Analysis of the data was multi-phased and involved data immersion, theoretical and open coding using the constant comparative method (Maykut \& Morehouse, 1994), creation of parent/child nodes, and thematic analysis (Strauss \& Corbin, 1998). The key relationship between data and theory is the conceptual code. Coding moves the analysis from the empirical level to the theoretical by capturing emerging themes that may be later theoretically conceptualized by identifying the underlying pattern(s). In this manner, coding provides a condensed, abstract view that connects the data logically and authentically.

The interview material was first analyzed by two of the researchers, following a three-step procedure to ensure reliable classification and interpretation. The sample size of 24 exceeds the recommended six to eight subjects required to achieve theoretical saturation (Crabtree \& Miller, 1992). The first step included data preparation to ascertain whether all interviews and transcripts were included in the analysis. The second step comprised data coding as guided by the Black (1988) and Black and Stephens (1989) three-facet expatriate adjustment model and other extant research. An initial hierarchical coding scheme for thematic categories (e.g., acculturation experiences, adjustment patterns, acculturative stressors and coping, assignment outcomes) was developed using 'parent' codes. New subordinate, or 'child', nodes were then added and refined according to findings from iterative readings. The third step involved data examination and interpretation, resulting in final re-coding and minor refinements. In this third step, peer debriefing was used to enhance the credibility and validity of the emerging themes (see Lincoln \& Guba, 1985). This was achieved through a vetting process throughout the iterative coding process on each theme until agreement was reached between the two researchers. This approach helps minimize bias within the inquiry and authenticate researcher interpretation (Spall, 1998: p. 281). The lead researcher's prior military experience provided insider insight and knowledge of the military culture, while the other two researchers have not worked in the 
military and hence could add academic distance to the analysis. This provided the benefit of insider and outsider status in the research (see Dwyer \& Buckle, 2009). The data analysis was performed with the aid of NVIVO 10, a software program that assists in the organization of qualitative coding.

\section{Results}

Given our close focus on the micro-context and daily life of the expatriates, our analysis generated well over 170 themes. These codes were organized hierarchically as guided by the acculturation and expatriation literature, in addition to context as influenced by location and time. Thirty-three child nodes and over 90 sub-child nodes were categorized under nine parent nodes including: acculturation experiences; adjustment patterns; acculturative stressors; acculturative coping; historical trends; reasons for joining; military context; assignment outcomes; and post-assignment outcomes. In this paper, though, we present only the themes relevant to the two research questions. As appropriate in a qualitative case study, we note the salience of themes as measured by their relative presence (or lack thereof) across occupations, ranks, and war zones. The percentages reflect how many veterans in a particular war zone commented on a specific theme (see Table 2).

Table 2

Key themes as percentage of responses across war zones.

\begin{tabular}{|c|c|c|c|c|}
\hline Parent-child & WWII (\%) & Korean War (\%) & Vietnam War (\%) & Gulf Wars (\%) \\
\hline General adjustment & 100 & 100 & 100 & 86 \\
\hline Living conditions & 67 & 67 & 20 & 71 \\
\hline Accommodations & 100 & 67 & 100 & 36 \\
\hline Interaction adjustment & 67 & 67 & 83 & 86 \\
\hline Experiencing a foreign culture & 67 & 33 & 60 & 50 \\
\hline Language differences & 0 & 33 & 60 & 21 \\
\hline Work adjustment & 100 & 100 & 100 & 93 \\
\hline Work conditions & 100 & 100 & 100 & 36 \\
\hline 24-7 nature of work & 100 & 67 & 60 & 53 \\
\hline Work responsibilities & 33 & 33 & 80 & 50 \\
\hline Deeply satisfying work & 67 & 100 & 80 & 64 \\
\hline Acculturative stressors & 100 & 100 & 100 & 100 \\
\hline Extreme context & 100 & 33 & 100 & 100 \\
\hline Gender-related & 67 & 33 & 80 & 93 \\
\hline Acculturative coping & 100 & 100 & 100 & 100 \\
\hline Relational resources & 67 & 100 & 80 & 100 \\
\hline Recreational coping & 100 & 100 & 80 & 78 \\
\hline Individual resources & 67 & 33 & 80 & 78 \\
\hline
\end{tabular}

Herein we expound on the themes that occurred most frequently in the analysis and across the greatest number of interviewees.

\subsection{Adjustment patterns}

The first Research Question asked "What are the general, interactional, and work-related adjustment patterns of female career military expatriates as shaped by an extreme context?" The findings are presented below with supporting evidence that illustrates the most common issues identified by the veterans' in responses as based on the three-facet adjustment model (Black, 1988; Black \& Stephens, 1989).

\subsubsection{General adjustment}

Themes related to general adjustment were categorized by the expatriates' reaction to the living conditions, which included the natural environment, and accommodations, food, and life in an expat ghetto. Both Korean and Gulf War veterans noted the extreme weather conditions, with the Gulf expatriates remarking on the intense heat in the desert and the constant presence of wind and sand, while another veteran recalled the bitter cold of the Korean winter. Comments across all war zones also noted the austerity of living and lack of privacy when living in a temporary situation with make-shift toilets and shower facilities. More importantly, veterans across all war zones reported that their unit was sometimes unprepared for women and as such accommodations (including latrines) would have to be hurriedly improvised. These types of incidents occurred more frequently in the conflicts prior to the Gulf Wars when the deployment of females into combat zones was still relatively new.

The quality of food depended on whether the expatriates were living on a well-established base with good infrastructure or less permanent quarters. Some interviewees reported enjoying fresh fruit and vegetables but many had to make do with "Meals Ready to Eat" (MREs). Typical of most soldiers' experiences, the MREs were not popular:

It all has a shelf-life of like 10 years and it all taste the same. It is designed to help constipate you on purpose, so when you're in a field environment, that eliminates that need from occurring often, so you can imagine how much fun that is. (Support, Officer, Gulf War) 
The type of accommodation varied based on the war zone and specific location and assignment. Women in both the Gulf War and the Korean War remarked on the challenges of residing in tents due to overcrowding and harsh weather conditions: “... then we didn't want to get out of the sleeping bags because then we had to go to the latrine-and there's a picture of that, too. It's a tent where the seats would be frozen" (Medical, Officer, Korean War).

Despite the challenging and occasionally harrowing conditions, most of the women typically described their experience of living in a forward combat setting in mostly matter-of-fact terms with complaints primarily centered around the weather and MREs (also known as "Meals Rejected by Everyone"); a military morale issue that American male soldiers have long noted (Severson, 2003).

\subsubsection{Interactional adjustment}

Themes related to experiencing a foreign culture (including interacting with locals), along with language-related issues, were coded under interactional adjustment. Contact with host nationals was limited as would be expected in a war zone. Most interactions occurred on base with allied forces and within the artificial confines of an expatriate ghetto. Interactions with civilian locals were mostly transactional, such as the hiring of laborers, or occurred during a rare off-base shopping excursion. Nonetheless, veterans across all war zones reported that they enjoyed meeting and socializing with locals, as exemplified by one Vietnam veteran who reflected on her experience of meeting 'tea girls' who cajoled Allied soldiers in to buying them expensive drinks in local bars. However, not all interactions were positive. Close analysis showed distinct differences in the type of interactional experiences based on the particular war zone. For example, women who participated in the Gulf Wars reported incidents of intimidation by host soldiers:

I hated it there because there were Saudi solders. And...the women would go out and try to run, the men would try to run you over with vehicles. They would throw things at you, and it got to the point that the men could go out, but we couldn't. The men could do this, but we couldn't. They would yell things at you. . .(Technical, Officer, Gulf War)

On their rare opportunities to go outside the military base, the Gulf War soldiers reported feeling discounted based on their gender: I went into a carpet store with this guy and the carpet owner was talking to him about the carpets and I said something and the guy totally ignored me. I just-like I wasn't even there (Technical, Officer, Gulf War). Unlike many of the female veterans in WWII, Korea and Vietnam who enjoyed traveling in-country, the shadow of terrorism appeared to dampen both the available opportunities for travel and the enthusiasm of the Gulf veterans to travel off-base and interact with locals, as one women noted: There was a couple of chances to get off post, but generally there was nothing more interesting than your work so you just kept on working (Technical, Officer, Gulf War). Other relevant factors may have been related to the distinct cultural differences between the US generally and the Gulf war regions (the latter being predominately Muslim), in respect to the role of women in society. For instance, analysis also revealed that some of the women complained about wearing the 'abaya' (long over garment which conceals the body neck to ankle and wrists) and not being allowed to drive, in contrast to their male counterparts who had more freedom of movement.

A minority of the veterans also remarked on language differences despite the fact that none of the women reported being able to communicate in the local dialect despite a stated interest in or attempt to use their host's language. For example, one Gulf War veteran recalled desperately trying to use a "stupid, little handbook" to communicate in dialect with locals during a tense standoff (Medical, Officer, Gulf War) suggesting that greater language proficiency in an extreme context has both operational and security value (see Fisher \& Hutchings, 2013).

As proposed earlier, the relatively limited interaction with host nationals may be a result of the veterans' choice to focus more on their mission than socializing outside of their own units, coupled with security concerns. Limited or lack of language skills may have also minimized interaction: only one Gulf War veteran reported receiving language training (in Arabic) prior to deployment.

\subsubsection{Work adjustment}

In this category, themes relating to the working conditions (including the use of personal protective gear for security) and responsibilities and the 24-7 nature of the work were coded. Additionally, the theme deeply satisfying work is presented here to clearly illustrate the veterans' response to a complex series of challenges to accomplishing their work in a combat zone.

The data revealed that working conditions varied across both war zones and occupations. An expatriate during WWII recalled how the soldiers initially lived and worked in foxholes:

So, we lived in foxholes. And that's when I learned why the Army told me to keep my butt down,'cause we had to crawl to the other foxholes and drag the kids back that were injured. And we had a-they made us a rather large foxhole, and that was the first aid station. (Medical, Officer, Multi-wars)

In contrast, a military nurse in the Korean War described her hospital as "a tent with just canvas over the dirt for the floor... with a potbellied stove..." (Medical, Officer, Korea), while a Gulf War veteran who was attached to the Judge Advocate General's (JAG) corps described her office as "very cushy" (Support, Officer, Gulf). Although veterans from the earlier wars complained about the heavy metal helmets and 'duffel bags' that they carried, it was surprising to learn that 50 years later, female veterans were still dissatisfied with the hot, heavy, poorly-fitting body armor and equipment required while on military duty. 
Irrespective of an individual's working conditions, a strongly shared theme was the deep satisfaction and pride in their expanded roles and responsibilities. As one Gulf War veteran stated, "... I was the first woman and the first nurse ever to hold that position. .. it was quite an awesome responsibility" (Medical, Officer, Gulf). Another woman recalled her first command role: "21 months. What an experience" (Technical, Officer, Gulf).

Another shared theme among both officer and enlisted and across all war zones was the 24-7 nature of the work: Everybody, we'd work, depending on the patient load, if we worked $16 \mathrm{~h}, 18 \mathrm{~h}$, until you were ready to flop, really, and then somebody else would take over until they were ready to flop (Medical, Officer, Korean War). Moreover, unlike their civilian counterparts, the veterans also had their military duties and responsibilities, which further compounded their seemingly unending workload:

But we worked 14-hour shifts because we had to work 12-hour shifts, but you had to go report an hour prior so you can get armed up...And then you got off after your 12 hours of working on post. Then it took another hour to turn in all your ammo and weapons. (Technical, Enlisted, Gulf)

Despite the long hours, extra duty, and, for many, poor working conditions, most of the women framed their work responsibilities as an 'adventure' and felt like they 'made a difference': I would have stayed two extra years. I knew I had a really unique experience. I say I would deploy again in a heartbeat (Technical, Officer, Gulf War). Not surprisingly, many of the women who presented their experiences within the context of 'making a difference' were in the medical field. Many of the veterans' memories are still vivid:

You could imagine how I felt listening to him. I almost cried. I felt a feeling of deep gratitude to God for helping this man came through that war alive. I felt a great pride and personal satisfaction and reward that I was able to help him (Medical, Officer, Vietnam).

\subsection{Acculturative stressors and coping strategies}

The second Research Question asked "What are the stressors of female career military expatriates in an extreme context and how are these stresses mitigated?" In this section, themes were categorized broadly by extreme context (the operational environment) or gender-related stressors. The various coping strategies were categorized as: relational-level resources, recreational activities, and individual-level resources.

\subsubsection{Acculturative stressors}

4.2.1.1. Extreme context. Themes that were categorized under extreme context included comments regarding the presence of danger and dealing with death and trauma. In a combat setting, there is the omnipresent danger of being killed or wounded in an attack. The female expatriates noted the possibility of chemical weapons, being overrun by the enemy, and incoming missile attacks. However, across all war zones, their reaction was consistently pragmatic. Here a Gulf War veteran recalls a typical reaction:

We had-always had SKUD missiles incoming. . . But I was working 18, 20 hour days from the start of-start of being deployed. . .I just kind of-my assumption was by the time it got to us it was too late. So I just stayed in bed and got my sleep. There was a couple that exploded right around us (Technical, Officer, Gulf War).

Although 3 out of 14 Gulf War veterans remarked on the horror of observing or cleaning up after a suicide bomber attack, 4 out of 9 medical officers who were in the first three wars remarked on the psychological strain of working with or seeing the dead and wounded. One Vietnam veteran recalled:

With a group of paramedics assigned to me, we would have the task to sort out bodies of dead soldiers that could come in plastic black bags and put them together, with heads, limbs of the same skin colors... (Starts to cry) (Medical, Officer, Vietnam).

Our findings support prior studies that show that medical personnel are more likely to experience emotional trauma associated with combat than other occupations (Wessely, 2005).

4.2.1.2. Gender-related stressors. Data analysis revealed gender-related stressors associated with being the first (or only) woman in a unit or role and this was coded across all war zones. Gender-related issues also encompassed challenges experienced by women who contested traditional roles, particularly as formal leaders, in addition to being sexually harassed or feeling discriminated. Additionally, the more serious issue of sexual harassment, including the potential for assault, was reported by a minority of the Gulf War (20\%) and Vietnam War (15\%) veterans.

Historically, US military women were not an official part of the military nor accorded the same privileges and pay as their male counterparts until The Women's Armed Services Integration Act of 1948 was passed. Not surprisingly, one of the WWII pioneers remarked on the challenges of being accepted as professionals and having suitable facilities available for women: "Nurses were classified as lower than low, in those days, right along with the evening ladies" (Medical, Officer, Multi wars). The same veteran recalled an incident regarding the appropriate design of latrine facilities, which was an issue for all the veterans prior to the Gulf Wars: 
Being women we always had to go to the bathroom, you know. So we got to one place, and all it was a slit trench. Now we're in slacks. So we went out to the chief nurse, and we said, "We can't use that, it's a slit trench!" So she walked up to this commanding officer, and she said, "The girls can't use that, it's a slit trench. Do you have any other thing?" He said, "Tell'em to deal with it."...She says to him, "My ladies are setters, not pointers. Fix it!" (Medical, Officer, Multi wars)

Post-Vietnam War, however, as women were more closely integrated into military units and began to occupy leadership roles in non-traditional fields (e.g. engineering, intelligence), analysis revealed a shifting focus of the complaints from being accepted as professionals to their positional role: I wanted to be treated with the same respect as the next guy, but it's, sometimes they still saw me as their sister type... (Technical, Enlisted, Gulf War). Without exception, though, all of the veterans who experienced being the 'first' military woman to assume a role (such as commander) or position (such as sharpshooter) relished the challenge and took pride in their accomplishments.

Sexual harassment from male co-workers, often under the connivance of superiors, was reported by Vietnam and Gulf war veterans, but was not noted by veterans from the Korean War or WWII era. This may be due in part to the relatively limited numbers of these women in our sample or simply greater reluctance by an older generation of women to discuss this topic. One officer recalled her experience while deployed:

I guess I'm a little disappointed and maybe they're not sweeping it under the rug as much now in this new Iraq, which I'm glad they're not, but you know, when you got a lot of guys over there sitting around doing nothing, you know, they get really stupid. I mean, we had peeping Toms; we had people try-and get raped...You know, at one point I just said, you know, we have more to fear from the males here than we do from the Iraqis (Technical, Officer, Gulf War).

\subsubsection{Acculturative coping strategies}

In respect to coping strategies, a number of significant themes emerged that were categorized as follows: relationallevel resources (communication with family and friends; co-worker support); recreational activities (drinking; socializing; working out); and individual-level resources (religion; controlling emotions; crying). Over 70\% of the veterans spoke about the importance of camaraderie and their ability to cope with the 24-7 nature of work and the constant danger of working in a war zone. One woman described nature of these bonds as being "almost as thick as blood" (Officer, Medical, Gulf). The expatriates also relied heavily on family and friends for their emotional/social support. Typical of deployed soldiers, the women reported sharing both their letters and care packages with their comrades.

In a war zone there is very limited leisure time. Many of the Gulf region veterans reported working out or running as a way to relieve stress; this did not appear to be an option or consideration for the veterans in earlier wars. Women in the wars prior to the Gulf also enjoyed drinking alcohol and partying with male counterparts and host country nationals. For Gulf War veterans, opportunities for entertainment were limited and illustrated the importance of on-site amenities for the expatriates, such as movies, pools, and sporting events.

Although it is a truism that there is "no atheist in a foxhole", one notable theme was the role of a strong religious faith in dealing with the daily stress of working and living in an extreme context. The following reflection is a typical example:

I really believe that you need, in the circumstances that I was in, to believe that there is a power beyond us human beings, that you need to ask that Power-whatever you want to call it, for me it is God, to please come down and help you, because you get to a point where you wonder if you are going to make it (Medical, officer, Vietnam).

Women also reported breaking down and crying as an emotional release, particularly during major traumatic events. One veteran recalls that she "... cried a lot. I talked to people who were in similar circumstances. I cried on the job. I must admit" (Technical, Enlisted, Gulf War). Some women reported, too, that they would cry with a male co-worker, without any shame or embarrassment felt by either party. In contrast to calling on their faith or crying, the veterans also reported that at times they actively controlled their emotions by going into 'denial' or pretending it "was like a movie in my head" (Support, Enlisted Gulf). A majority of the Vietnam War medical veterans recalled playing pranks on their supervisors or co-workers as a welcome relief from the unrelenting horror of treating wounded soldiers.

\section{Discussion}

The aim of our study was not to broadly generalize across all expatriates, but to deeply examine, through a phenomenological lens, the lived acculturation experiences of a type of public sector expatriate with a particular emphasis on female gender and as shaped by an extreme context. In doing so, our study also offers useful insights for female expatriates of similarly tasked organizations that operate in highly dangerous settings by highlighting the multiple challenges of working and living in an extreme context. The analysis also revealed that when confined to an expatriate ghetto as mandated in a dangerous, demanding environment, general and work adjustment were found to be salient to a stronger degree than interactional adjustment. The implication is that the relevance of each of the three dimensions of expatriate adjustment is influenced by the particular context in which the expatriate operates. Specifically, the women in our study revealed a tendency to 'get the job done' despite conditions characterized by extreme danger, nominal domestic comforts, and unrelenting work requirements in culturally unfamiliar contexts. Their professional commitment, along with the important role of camaraderie, facilitated their coping and adjustment, thus they did not necessarily need to interact with host country nationals or explore the country. However, our study also revealed that while challenging living conditions and limited 
intercultural contact might be of less importance when expatriates spend most of their time at work or in their protected military complexes or expatriate 'ghettos', the restricted freedom for Western military women in a conservative, Islamic country may create an added acculturative stressor. These findings critique an assumption within acculturation literature that acculturation must entail effective engagement with local people, while forefronting the importance of contextual features of both the organization and the environment.

Likewise, while much of the extant literature on expatriate adjustment and acculturation has shown that the perceived quality of living conditions and the host country's threat level contribute to stress levels (Bader \& Berg, 2013), our findings suggest that the female expatriates were mostly pragmatic and resilient in their approach to dealing with difficult circumstances and adapted over time to the extreme context despite having to contend with gender-specific stressors as reported by deployed military women (Street et al., 2013) and expounded on in our study. Additionally, the women drew heavily on individual-level resources such as prayer and crying, along with relational-level resources such as communication with loved ones, to cope with the non-stop work demands and constant presence of danger. These findings highlight the salience of relationships with family and colleagues (Caligiuri \& Lazarova, 2002) rather than host nationals. Similar to their male military counterparts (see Sasson-Levy, 2008), many of these pioneering women were also drawn to the 'adventure' of working in a combat zone and relished the increased scope of their professional responsibilities. Overall, these female career military expatriates demonstrated shared coping strategies and traits that are closely linked to psychological resilience (Reich, 2006) and this challenges prior research suggesting women expatriates struggle with isolation and stress (Tung, 2004).

The rich, qualitative data allowed for a nuanced analysis that corroborated the changing roles of women's international careers in Western society (see Altman \& Shortland, 2008) over the past six decades-as reflected in the growing involvement of women in the US military (DoD, 2011). The interviews revealed the expanding technical and support roles available to women, which presented its own set of challenges as women assume leadership roles in non-traditional jobs. However, the findings also suggest that the US military continues to play 'catch up' with providing female members with basic necessities as their roles continue to evolve. As noted by veterans of the more recent Gulf Wars, this took the form of inappropriately-sized body armor and equipment.

A more serious and ongoing gender-specific stressor, however, was the presence of sexual harassment and the associated threat of sexual violence for female veterans. The comparison of female expatriate experiences across war zones showed important differences emerging from the analysis. Namely, for Gulf War veterans, the perceived resistance from the host country to accepting women in managerial roles and being treated differently than their male counterparts was a significant stressor noted by almost $60 \%$ of the women. Despite the military's own studies that suggest military women in general are not at significantly greater risk of sexual assault ${ }^{1}$ than their civilian counterparts, there is evidence of increased risk with multiple overseas deployments (DoD, 2012). Indeed, in a separate study, military women who deployed to the Gulf regions reported experiencing a greater threat of sexual assault and harassment by both host nationals and their own counterparts (Street et al., 2013). These findings provide additional insight into prior research that suggests differences between cultures (e.g. between Eastern and Western cultures) have been associated with war atrocities as it allows the soldier to dehumanize the victim (see Grossman, 1995) and this has been noted in relation to not only conflict with local military but also actions like rape of local civilian women as war crimes which has occurred throughout the history of war (see Watts \& Zimmerman, 2002). The seriousness and relevance of these gender-related issues for military female expatriates has been noted in military-sponsored studies (See DoD, 2012; Street et al., 2013) and is an issue deserving of attention especially by leaders at all levels of organizations that operate in dangerous settings. Indeed, a Safety First report provided by the Save the Children organization (Save the Children, 2010) cautions females sent overseas about the increased risk of rape and they are advised to carry a 'rape kit' that contains post-exposure prophylaxis (PEP).

In extending research to expatriates outside the business community and who work in a dangerous setting, we have identified that female military expatriates can effectively adjust despite facing added stressors that may be gender-specific (see Tung, 2004), and that they may adjust similarly to men (see Selmer \& Leung, 2003). The oral histories further challenge research that suggests that women's overall job satisfaction may be lower (Culpan \& Wright, 2002), and they appear to struggle more with the stress and isolation of an overseas posting (Tung, 1998). In looking back over their military career, many of these female pioneers were grateful for the remarkable professional experiences and personal relationships that they had enjoyed. While some research has noted specific stressors and issues for coping encountered by women (see Hutchings et al., 2013; Mäkelä et al., 2011) and consideration has been given by researchers to the relative fit of male and female expatriates in the corporate world, this research identifies the need to understand women's acculturation in other contexts.

\section{Limitations, issues for future research, and implications}

Issues regarding recall must be acknowledged as a limitation of this study given that 10 out of 24 veterans were recalling events that occurred over 40 years ago. Most research supports the trauma superiority argument which states that

1 The DoD (2012: 53) definition of sexual assault encompasses both penetrating and non-penetrating sexual offenses and attempts to commit these offenses. 
trauma may enhance memory rather than impair it (Peace \& Porter, 2004). Thus we would expect that the interviewees were able to reflect not just on negative experiences but also highlight their positive career and interaction experiences. Further, respondent issues are notable such as when an interviewee embellishes a response, gives a response that is "socially desirable", or omits relevant information (Fontana \& Frey, 2000). These limitations were addressed in part by presenting only the themes that emerged consistently across the majority of the 24 interviews thus allowing for reliability of responses. Furthermore, many of our participants shared frank assessments of their experiences and reactions, indicating that rosy retrospective bias may not be a major cause for concern (Mitchell \& Thompson, 1994). Though we feel our method of exploring the lived acculturation of female military expatriates was appropriate for our goals, we recommend that future research explore to what degree these salient themes are shared across different national contexts and public sector occupations.

Given the serious nature of sexual harassment and threat of sexual violence as reported by the veterans, future studies should focus on how these gender-specific stressors impact the acculturation process for women in dangerous settings and how their lived experiences impact their repatriation or willingness to remain with the organization. It would also be useful for future research to examine the experiences of non-career female military expatriates to highlight any differences in acculturation stressors and consequent organizational commitment. Also, further investigation of specific gender-related challenges associated with host country context is warranted in respect to whether acculturation and organizational commitment differ between males and females in relation to local norms and codes of behavior and women being more 'ghettoed' in some societies than their male counterparts. Associated with this, while we highlighted some differing views of women across war zones, future research might undertake a direct comparison of the experiences of female military expatriates who served in their traditional military role (with limited contact with locals) and those who were closely involved in working directly with the host nationals and the degree of acculturation to local environment and the types of coping strategies utilized. Further, future research might also explore whether ethnicity of the expatriates (and not just their nationality) impacts on their acculturation experiences (including stressors), particularly in relation to engagement with, and commitment to, the local context. Future research might also provide direct comparison with the recollections of male military expatriates to identify if time and commitment affected the genders differently. Our analysis of the observations of female military career expatriates provides perceptions of those working in one form of extreme context and though this context has received limited reference in the expatriate acculturation literature, future research could also examine women who have worked as aid workers, journalists, photographers, and humanitarian peace workers in societies beset by war, civil disorder, or extreme poverty, in order to identify differing acculturation experiences.

The research highlights that as the women often had limited opportunities for interaction with local communities and worked in real and virtual expatriate ghettoes, they relied very much on camaraderie and support from their fellow military expatriates. While professional commitment was a critical aspect of what kept them focused in challenging cross-cultural contexts, the findings suggest the importance for organizations across all sectors which are operating in extreme contexts to provide opportunities to develop collegial mentoring and knowledge sharing particularly for people like aid workers and foreign correspondents who spend much of their careers in 'hot zones'.

\section{References}

Altman, Y., \& Shortland, S. (2008). Women and international assignments: Taking stock-A 25 year review. Human Resource Management, 47(2), 199-216. Aycan, Z. (1997). New approaches to employee management. In D. M. Saunders, \& Z. Aycan (Eds.), Expatriate management: Theory and research (vol. 4) (pp. 1-40). New York, NY: Elsevier Science/JAI Press (D.M. Saunders (Series Ed.) \& Z. Aycan (Vol. Ed.))

Bader, B., \& Berg, N. (2013). An empirical investigation of terrorism-induced stress on expatriate attitudes and performance. Journal of International Management, 19(2), 163-175.

Berg, B. (1995). Qualitative research methods for the social sciences (2nd ed.). Boston, MA: Allyn and Bacon.

Berry, J. W. (2005). Acculturation: Living successfully in two cultures. International Journal of Intercultural Relations, 29(6), 697-712.

Berry, J. W., \& Kailin, R. (1995). Multicultural and ethnic attitudes in Canada: An overview of the 1991 national survey. Canadian Journal of Behavioral Sciences, 27, 301-320.

Björkman, I., \& Schaap, A. (1994). Outsiders in the middle kingdom: Expatriate managers in Chinese-Western joint ventures. European Management Journal, $12(2), 147-153$.

Black, J. S. (1988). Work role transitions: A study of American expatriate managers in Japan. Journal of International Business Studies, 19(2), 277-294.

Black, J. S., Mendenhall, M., \& Oddou, G. (1991). Toward a comprehensive model of international adjustment: An integration of multiple theoretical perspectives. Academy of Management Review, 16(2), 291-317.

Black, J. S., \& Stephens, G. K. (1989). The influence of the spouse on American expatriate adjustment and intent to stay in Pacific Rim overseas assignment. Journal of Management, 15(4), 529-544.

Bolino, M. C. (2007). Expatriate assignments and intra-organizational career success: Implications for individuals and organizations. Journal of International Business Studies, 38, 819-835.

Caligiuri, P., \& Lazarova, M. (2002). A model for the influence of social interaction and social support on female expatriates' cross-cultural adjustment. International Journal of Human Resource Management, 13(5), 761-772.

Crabtree, B. F., \& Miller, W. L. (1992). Doing qualitative research. Newbury Park, CA: Sage.

Crowley-Henry, M., \& Heaslip, G. (2014). Short-term international assignments. Military perspectives and implications for international human resource management. European Management Journal, 32, 752-760.

Culpan, O., \& Wright, G. H. (2002). Women abroad: Getting the best results from women managers. International Journal of Human Resource Management, 13(5), 784-801.

DoA [Department of the Army]. (2010). Assignments, details, and transfers: Overseas service. Washington, DC: Office of the Deputy Chief of Staff. Retrieved from 〈http://www.apd.army.mil/pdffiles/r614_30.pdf〉. 
DoD [Department of Defense]. (2010). Demographics 2010: Profile of the Military Community. Washington, DC: Office of the Deputy under Secretary of Defense. Retrieved from 〈http://www.militaryonesource.mil/12038/MOS/Reports/2011_.

DoD [Department of Defense]. (2011). Demographics 2011: Profile of the Military Community. Washington, DC: Defense Manpower Data Center, Office of the Deputy under Secretary of Defense. Retrieved from 〈http://www.militaryonesource.mil/12038/MOS/Reports/2011_Demographics_Report.pdf〉.

DoD [Department of Defense]. (2012). Annual report on sexual assault in the Military, FY2012. Washington, DC: Defense Manpower Data Center, Office of the Deputy Under Secretary of Defense. Retrieved from 〈http://sapr.mil/public/docs/reports/FY12_DoD_SAPRO_Annual_Report_on_Sexual_AssaultVOLUME_ONE.pdf).

Doucerain, M., Dere, J., \& Ryder, A. G. (2013). Travels in hyper-diversity: Multiculturalism and the contextual assessment of acculturation. International Journal of Intercultural Research, 37(6), 686-699.

Dwyer, S. C., \& Buckle, J. L. (2009). The space between: On being an insider-outsider in qualitative research. International Journal of Qualitative Research, $8(1), 54-63$

Fenner, C. R., \& Selmer, J. (2008). Public sector expatriate managers: Psychological adjustment, personal characteristics and job factors. International Journal of Human Resource Management, 19(7), 1237-1252.

Fischlmayr, I. C., \& Kollinger, I. (2010). Work-life balance: A neglected issue among Austrian female expatriates. International Journal of Human Resource Management, 21(4), 455-487.

Fisher, K., \& Hutchings, K. (2013). Making sense of cultural distance for military expatriates operating in an extreme context. Journal of Organizational Behavior, 34(6), 791-812.

Fontana, A., \& Frey, J. H. (2000). The interview: From structured questions to negotiated text. In D. L. Denzin, \& Y. S. Lincoln (Eds.), The handbook of qualitative research (2nd ed., vol. 4, pp. 645-672). Sage: Thousand Oaks, CA.

Gil, A. G., Vega, W. A., \& Dimas, J. M. (1994). Acculturative stress and personal adjustment among Hispanic adolescent boys. Journal of Community Psychology, $22(1), 43-54$.

Goodman, R. S., \& Kruger, E. J. (1988). Data dredging or legitimate research method? Historiography and its potential for management research. Academy of Management Review, 13(2), 315-325.

Graves, T. (1967). Psychological acculturation in a tri-ethnic community. Southwestern Journal of Anthropology, 23(4), 337-350.

Grossman, D. (1995). On killing: The psychological cost of learning to kill in war and society. Boston, MA: Little, Brown and Company.

Halsberger, A. (2007). Gender differences in expatriate adjustment. In Paper presented at the Academy of Management Annual conference Philadelphia, PA.

Hannah, S. T., Uhl-Bien, M., Avolio, B. J., \& Cavarretta, F. L. (2009). A framework for examining leadership in extreme contexts. The Leadership Quarterly, 20, 897-919.

Harmer, A., Stoddard, A., \& Toth, K. (2013). The new normal: Coping with the kidnapping threat. In Aid worker security report 2013. Retrieved from 〈http://aidworkersecurity.org/〉 (accessed 7th July 2014).

Harrison, D. A., Shaffer, M. A., \& Bhaskar-Shrinivas, P. (2004). Going places: Roads more and less traveled in research on expatriate experiences and performance. In J. Martocchio (Ed.), Research in Personnel and Human Resources Management (pp. 199-247). Stamford, CT: JAI.

Harvey, M., \& Moeller, M. (2013). Call for papers-Acculturation experiences of overseas assignees and assignments. International Journal of Intercultural Relations,. Retrieved from 〈www.intercultural-academy.net/files/cpf_ijir_si_Lived_Acculturation_Experiences.pdf) (accessed 1st January 2014).

Husserl, E. (1962). Ideals: General introduction to pure phenomenology. New York, NY: Collier.

Hutchings, K., Michailova, S., \& Harrison, E. C. (2013). Neither ghettoed nor cosmopolitan. Management International Review, 53(2), 291-318

Institute of Medicine (IOM). (2012). Treatment for posttraumatic stress disorder in military and veteran populations: Initial assessment. Washington, DC: The National Academies Press.

Kealey, D. J. (2004). Research on intercultural effectiveness and its relevance to multicultural crews in space. Aviation Space and Environmental Medicine, 75(7), C58-C64

Lazarus, R. S., \& Folkman, S. (1984). Stress, appraisal, and coping. New York, NY: Springer.

Lincoln, Y., \& Guba, E. (1985). Naturalistic inquiry. Beverly Hills, CA: Sage.

Maguen, S., Ren, L., Bosch, J. O., Marmar, C. R., \& Seal, K. H. (2010). Gender differences in mental health diagnoses among Iraq and Afghanistan veterans enrolled in Veterans Affairs health care. American Journal of Public Health, 100(12), 2450-2456.

Mäkelä, L., Känsälä, M., \& Suutari, V. (2011). The roles of expatriates' spouses among dual career couples. Cross Cultural Management: An International Journal, $18(2), 185-197$

Maykut, P., \& Morehouse, R. (1994). Beginning qualitative research: A philosophic and practical guide. London: The Falmer Press.

McPhail, R., Fisher, R., Harvey, M., \& Moeller, M. (2012). Staffing the global organization: “Cultural nomads”. Human Resource Development Quarterly, 23(2), 259-276.

Mitchell, T., \& Thompson, L. (1994). A theory of temporal adjustments of the evaluation of events: Rosy prospection \& rosy retrospection. In C. Stubbart, J. Porac, \& J. Meindl (Eds.), Advances in managerial cognition and organizational information processing (pp. 85-114). Greenwich, CT: JAI.

National Research Council. (2012). Treatment for posttraumatic stress disorder in military and veteran populations: Initial assessment. Washington, DC: The National Academies Press.

Navara, G. S., \& James, S. (2002). Sojouner adjustment: Does missionary status affect acculturation? International Journal of Intercultural Relations, 26(6), 695-709.

Nuciari, M. (2000). Women in the military: Sociological arguments for integration. In G. Caforio (Ed.), Handbook of the sociology of the military (pp. 270-298). New York, NY: Springer.

Nutt, P. C. (2006). Comparing public and private sector decision-making practices. Journal of Public Administration Research and Theory, 16(2), 289-318.

Organista, P. B., Marin, G., \& Chun, K. (2010). The psychology of ethnic groups in the United States. Thousand Oaks, CA: Sage.

Peace, K., \& Porter, S. (2004). A longitudinal investigation of the reliability of memories for trauma and other emotional experiences. Applied Cognitive Psychology, 18(9), 1143-1159.

Reich, J. (2006). Three psychological principles of resilience in natural disasters. Disaster Prevention and Management, 15(5), 793.

Sasson-Levy, O. (2008). Individual bodies, collective state interests: The case of Israeli combat soldiers. Men and Masculinities, 10(3), 296-321.

Save the Children. (2010). Safety first: A safety and security handbook for aid workers. Retrieved from (http://www.eupst.eu/html/FranceMat/ 2.\%20Manuals\%20and \%20Guidelines/Save\%20the\%20children_Safety\%20First.pdf (accessed 6th August 2014).

Segal, D. R., \& Segal, M. W. (2004). America's military population. Population Bulletin 59, no. 4 (Washington, D.C; Population Reference Bureau).

Selmer, J., \& Fenner, C. R. (2009). Job factors and work outcomes of public sector expatriates. Human Resource Management Journal, 19(1), 75-90.

Selmer, J., \& Leung, A. M. (2003). International adjustment of female vs male business expatriates. International Journal of Human Resource Management, $14(7), 1117-1131$.

Severson, K. (2003). A lot of cooks in the MRE kitchen. San Francisco, CA: Chronicle (pp. A-20, accessed 27th March 2014).

Smith, J. K. (1983). Quantitative versus qualitative research: An attempt to clarify the issue. Educational Researcher, 12(3), 6-13.

Spall, S. (1998). Peer debriefing in qualitative research: Emerging operational models. Qualitative Inquiry, 4(2), 280-292.

Stahl, G. K., Miller, E. L., \& Tung, R. L. (2002). Toward the boundaryless career: A closer look at the expatriate career concept and the perceived implications of an international assignment. Journal of World Business, 37(3), 216-227.

Stening, B. W. (1994). Expatriate management: Lessons from the British in India. International Journal of Human Resource Management, 5(2), 385-404.

Strauss, A. L., \& Corbin, J. M. (1998). Basics of qualitative research: Grounded theory procedures and techniques (2nd ed.). Newbury Park, CA: Sage.

Street, A. E., Gradus, J. L., Hannah, L., Giasson, H. L., Vogt, D., \& Resick, P. A. (2013). Gender differences among veterans deployed in support of the Wars in Afghanistan and Iraq. Journal of General Internal Medicine, 28(2), S556-S562. 
Takeuchi, R. (2010). A critical review of expatriate adjustment research through a multiple stakeholder view: Progress, emerging trends, and prospects. Journal of Management, 36(4), 1040-1064

Tharenou, P. (2009). Women's self-initiated expatriation as a career option and its ethical issues. Journal of Business Ethics, 95(1), 73-88.

Thomas, D. C., \& Lazarova, M. B. (2006). Expatriate adjustment and performance: A critical review. In G. K. Stahl, \& I. Björkman (Eds.), Handbook of research in international human resource management (pp. 247-264). Northampton: Edward Elgar Publishing Limited.

Tung, R. L. (1998). American expatriates abroad: From neophytes to cosmopolitans. Journal of World Business, 33(2), 125-144.

Tung, R. L. (2004). Female expatriates: The model global manager? Organizational Dynamics, 33(3), 243-253.

Watts, C., \& Zimmerman, C. (2002). Violence against women: Global scope and magnitude. The Lancet, 359(9313), 1232-1237.

Wessely, S. (2005). Shell shock to PTSD: Military psychiatry from 1900 to the Gulf War. Hoboken, NJ: Taylor \& Francis Ltd.

Williams, C. L., \& Berry, J. W. (1991). Primary prevention of acculturative stress among refugees: Application of psychological theory and practice. American Psychologist, 46(6), 632-641. 